\title{
E-service portal for freelance community: case study in photography business
}

\author{
Supaporn Chai-Arayalert, Supattra Puttinaovarat, Nattaporn Thongsri \\ Faculty of Science and Industrial Technology, Prince of Songkla University, Surat Thani Campus, Surat Thani, Thailand
}

\begin{tabular}{l}
\hline \hline Article Info \\
\hline Article history: \\
Received Jan 26, 2021 \\
Revised Sep 9, 2021 \\
Accepted Oct 2, 2021 \\
\hline
\end{tabular}

Keywords:

E-service

Freelancers

Photography business

Web portal

\begin{abstract}
This study revealed the limitations of freelancers' inability to perform portfolios and biographies, their performance ratings to a large community of customers. The difficulties were evident in searching for reliable, qualified and experienced freelancers from multi-channel information sources. These limitations might impact the ability of freelancers selected by customers to perform the required task to the customers' satisfaction. This research focused on the case study of the freelance community for photography business in southern of Thailand. This aims to establish an online facility in which freelance photographers can publicize their services and performance to potential customers. The concepts entailed in web portals and e-services were the key elements in the development and ensured that its functions worked efficiently. The study employed qualitative methods were used to assess the current practices of web portal and thus determining the requirements for the e-service web portal for freelance community. The practical contribution is that it can aid the effective design and implementation of an e-service web portal for the freelance community of photography business, and it is a massive step towards promoting the freelance community in Thailand.
\end{abstract}

This is an open access article under the CC BY-SA license.

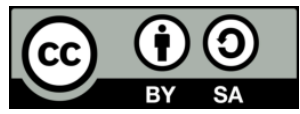

\section{Corresponding Author:}

Supaporn Chai-Arayalert

Faculty of Science and Industrial Technology, Prince of Songkla University, Surat Thani Campus

Mueang Surat Thani District, Surat Thani 84000, Thailand

Email: supaporn.chai@psu.ac.th

\section{INTRODUCTION}

The influence of e-businesses has changed the face of the photography business and careers by creating a larger number of freelance or independent photographers who hire out their services [1], [2]. In 2011, Adler and Sillars [3] studied that the initial problem is difficult to become widely known since one's reputation spreads only by word of mouth. Therefore, in order to have more customers, one's work must be good and it may be difficult for newcomers to the photography profession to obtain work if they are unknown to their potential customers and have no pre-existing reputation. The fact that customers do not know newcomers may lead to unwillingness to rely on them while, at the same time, potential customers may not know how to approach photographers who are new to the field, nor will those photographers necessarily understand the customers' requirements and thus produce work as required by them. To solve these problems, apart from having acquaintances as customers or relying on word of mouth, photographers must look for opportunities to make themselves known to the public, for instance, by advertising their ability on webboards or other media [1], [2]. There is an important way of gaining contacts, showing one's professional profile on social network, blogs, or websites, sharing and posting one's portfolio with contact details on the social media of related photography associations or establishing photography associations among peers. In 2013, Photoshelter and Agency Access, conducted a survey relating to how customers gain access to and assess photographers' 
services among 340 American users who had used such services in the United States. The results revealed that the users accessed photographers through search engines (42.1\%), from the photographers' web directory (25.2\%), from web portfolios $(12.1 \%)$, from friends and acquaintances $(10.5 \%)$, and direct from the websites of individual photographers $(10.2 \%)$ [4]. The survey also revealed the most important factor that helped customers to gain convenient and rapid access to photography businesses and services was the use of online media. Despite the availability of online business sites such as Upwork, Freelancer, Guru, and which provide services for freelance workers, such websites do not specifically focus on freelance photography nor have they developed their systems to cover their employment in the context of Thailand.

The inspiration for this project came from the requirements of the business community in southern of Thailand, who wanted to connect with the freelance photographers through an online medium. The attempt to establish a web portal to allow freelance community in the Southern region of Thailand to take advantage of web portal technologies was a significant step. This is understandable given that this was a very forwardlooking, and innovative project. It would probably have been better to scope of the portal and to treat it as a pilot project. Web portals provide a blend of information, applications and services. They are a single point of access to information [5], [6]. The importance of developing web portals is continuously attracting users by serving as a gateway to information or services with specific interests. The satisfaction of users is a primary goal for the development and operation of web portals [7].

This study therefore focuses on the development of web portal for freelance photographers and also on dealing with a number of issues relating to the hiring of freelance photographers. The first issue is that the main methods of making contact with photographers in order to hire one are by using the telephone or by personal contact and, in the past, these were the main means by which a photographer might introduce her/himself to those seeking photography services. However, with the availability of social media [1], [2], while photographers can conveniently introduce themselves and their work to potential customers without actually meeting or speaking with them, this leads to the problem that as the number of photographers increases, so does the amount of photographers' work that can be viewed online, and it may be less likely that a potential customers view a specific details because of the large number of portfolios available online. Second, it may be difficult for customers to locate skilled and experienced photographers with the required qualifications because information obtained from websites may not be completely reliable, and this may lead to the customer being dissatisfied with the work produced, which may lead to late or disputed payment of the fee.

This leads to the research question "How can e-service web portals be designed and developed, in particular for the freelance community case study in photography business?". The research objective is to design and develop the e-service web portal for freelance photographers. It offers a digital platform where buyers and freelance photographers can meet and take actions to deal with each other. In light of these issues, this study proposes a web portal with the particular aim of allowing photographers to introduce their work and manage and disseminate information relating to their services. The following section of this article reviews previous literature relating to web portals and is followed by a review of e-service. The research methodology is then presented, followed by a description of the implementation and the results of a system evaluation, and the paper ends with discussion and a conclusion.

\section{BACKGROUND}

\subsection{Web portal}

Web portals are designed as innovative self-service technologies that offer a single point of access to information and services, almost unlimited content as well as applications and excellent retrieval facilities that enable one-stop service [8], [9]. By integrating a web portal technology with existing business processes, portal owners hope to create an effective channel to communicate with users, as well as other stakeholders. For potential users, web portals are a platform that enables them to become acquainted with an organization, to explore its goods and services, and to make inquiries. For existing users, web portals are a place to become more familiar with the organization, to obtain product and service-related information, to request services, and to exchange information with peer users of the same goods and services. With online business now playing such an important role in the economy, there has been a rapid increase in the number of people opting to work as freelance photographers [2], allowing them to work independently and sell their services and work to a wide range of companies and individuals. They can also be more flexible in regard to the place and time that they work, which can be either full-time or part-time. Flexibility and independence are the keys to this important transformation. Having a pool of independent workers answers the business problem of employers needing to employ varying numbers and types of workers based on their workload and the abilities required. Despite the availability of portal sites such as Upwork, Freelancer, Guru, and which provide a variety of services on freelancers, such websites neither specifically focus on the information of freelance photography services nor develop their systems to cover the employment features in accordance with the Thai context. 
A community web portals evolved from web communities of interest, in which portals were created to meet the interests of a specific group and can be defined geographically [7], [10]. This community web portal is defined as an Internet facilitated gateway for a community of freelance photographers (subscribers), providing standardized access to other subscribers, resources and functions. Users navigate to access a range of goods and services offered by the portal. Therefore, the community web portal of freelance photographers acts as a moderator between freelancers (or suppliers of services) and buyers of services and earns revenue from a marginal fee or a percentage of the total payment transaction. This research creates a platform to post job vacancies and lets freelancers to add their profile and services on the portal sites. The buyers of services are the clients' bringing jobs to the marketplace, while the sellers are the freelancers looking for work.

\subsection{E-service concept}

An electronic service (e-service) is an interactive, and web-based service. An e-service is provided through a virtual environment that covers various business operations, such as management, marketing, sales, advertising, and public relations [11]-[13]. In this study, a particular e-services technology was employed in which users were able to conduct different forms of operations themselves. The e-service are described in [9], [14] covering the core, facilitating, and supporting e-services. The main objective of this research is to create a web portal as an e-service for photographers and potential customers who want to hire photographers. Based on the literature review [9], [14], [15], the following contents of the e-service for freelance photographers were established in this study.

The core e-services are the basic and main services of businesses. The core e-services are designed to meet the primary demand need of a particularly described target group, including the management of photographers' portfolios and profiles, information about photographers, the ability to upload and share photographs and albums and to search for photographs and photographers, stock photographs and photograph descriptions including image-editing descriptions and photo album organization. The facilitating e-services enable to use the core e-services, including registration, reviews and comments, communication channels and privacy policy. The supporting e-services are used for increasing value or in order to distinguish the core eservices among services provided by competitors, and help both the core, and facilitating e-services. The supporting e-service consists of communication channels and notification services.

Therefore, the e-service web portal for freelance photographers integrates both photographers' information and their portfolios. In addition, it contains tools to allow search for information and the sharing of knowledge and experience. It acts as an e-service through which both photographers and their customers can achieve their aims. The photographers are able to record and disseminate information and promote their work while the customers can search for the photographers and photography types they require. Customers can additionally express their opinions and rate the performance of the photographers.

\section{RESEARCH METHOD}

This research was conducted in a qualitative approach. The methods of data collection were comprised of document analysis and interviews, and data was analyzed and developed into an e-service portal application and, finally, system evaluation related to the efficiency of the proposed system was performed. Participants are 30 members of the photography club, freelance photographers or potential customers. The profiles of participations are that $90 \%$ are aged between 18 and 21 , and $93.33 \%$ have been using the Internet for more than 4 years. $36.67 \%$ of participants have used photographers or photography services for graduations, weddings, and ceremonies. Participants acknowledge information or use the photographer services from social media, friends, and websites respectively.

In this study, an evolutionary prototype was created as a visualized simulation of the system. Then its capabilities were extended until all the functions needed for the actual system were available according to the users' requirements [16]. The users participated in all stages of the prototype development which enabled them to understand the overall system so that they were subsequently able to easily operate it [17]. The prototyping development began by selecting the main functions and creating the prototype. Then the system was evaluated by the users and the prototype was adjusted based on any recommendations from the users. When the initial prototype was accepted, it was developed and more functions for other phases were added until it was completely developed. At that stage, system testing was conducted.

The design and development of an e-service web portal involves gathering the requirements, developing and refining the prototype, and implementing a real system. Firstly, the gathering requirement is the users' needs were determined through interviews relating to requirements and potential problems, which were summarized in a user requirement and a system specification. Secondly, conducting a quick design, creating a prototype, evaluating the prototype, and refining the requirements, a system prototype was developed to allow the users to easily and quickly understand the system and to enable them to rapidly evaluate the appropriacy of the system for their requirements. The outcome was a prototype that was accepted by the users.

E-service portal for freelance community: case study in photography business (Supaporn Chai-Arayalert) 
The design was conducted based on the users' requirements by designing the main module of the system, then developing a prototype by placing the required contents in their positions on a layout. This design process helped the users to understand the simulation of the system being developed. The users are then able to try out the prototype and give feedback. Components which were identified as missing or unsatisfied by the users were then improved and the prototyping system was then developed to its final result. Thirdly, the prototype was further developed and was upgraded to a real application. The system testing was conducted to ensure that the system works in accordance with the system objectives and the users' needs, while mistakes which may occur when the software is used in a real environment are prevented.

\section{RESULTS AND DISCUSSION}

\subsection{System overview}

The system, as illustrated in Figure 1, is divided into three modules of functions and services, including core e-services, facilitating e-services and supporting e-services. Additionally, this system integrates the $4 \mathrm{C}$ of web portal aiming to support the operation and quality of the e-service web portal. First, web portal contains primarily of content from different structures, formats, and standards. Web portal's activities include the collection, selection, systematization, processing and distribution of information. It should provide an easy way to access relevant content [18], [19]. Its content is all related information and services that are necessary for supporting the closure of business deals efficiently. The availability of relevant, accurate and quickly accessible information on portals is important function of web portals [20], [21]. Second, web portal is characterized mainly through the aggregation, sorting and processing of information. Web portal should minimize customer effort through a playful and smooth navigation as well as a logical order of information presentation [20], [22], for example, search engines and directories that structure the portal's information and provides the possibility to find an optimal offer immediately. In addition, web portal arranges the ability to monitor and control the system's security [19]. Third, web portal provides infrastructures that help the effective communication between users [18], [19]. Web portal contains not only the communication from the user to the web portal provider but also the interaction between the users themselves. Various tools are available, for example e-mails, chats, and discussion forums. Communication tools facilitate the exchange of information and the building of long-term contacts to other users [20], and as a way of helping efficient work collaborations [6], [23], [24]. Forth, web portal conducts and handles the business transactions over the Internet. Web portal provides both sellers and buyers an efficient environment.

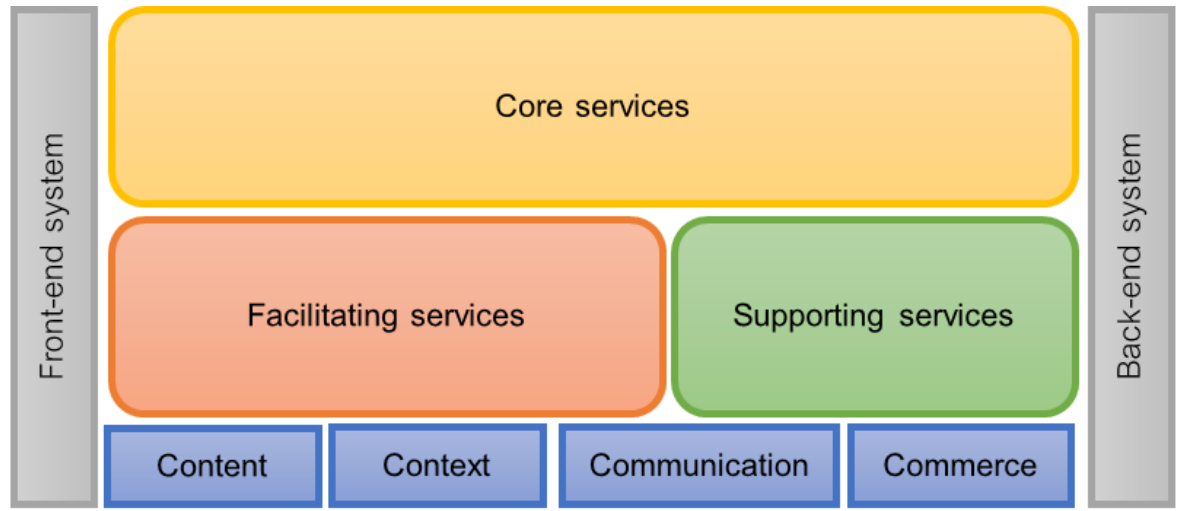

Figure 1. System overview of e-service web portal

The system focuses on two main groups of users: freelance photographers (suppliers of services) and customers (buyers of services). Customers are able to conduct searches for information themselves and obtain interesting information relating to photography, while a specific section is provided for them to express their opinions and exchange ideas. Customers search for information by typing in keywords, such as a photographer's name, a venue where the service is required, a hiring rate or a type of photography. They can also observe the photographers' information and profile prior to hiring that photographer and the customers can comment about and rate the photographer's performance after they have used their service. Photographers must apply as members listed in the system and their identities are inspected and confirmed prior to their being entered on the list of photographers in the system. The system can also record the photographers' personal 
information and display their portfolio, and also includes details of venues and places where they can work as well as their hiring rates and the means by which they can be contacted directly.

In the front-end system, photographers who want to sell photography services on a portal, must register themselves. When registration is complete, their biography, hiring rates, and are provided. Photographers can manage their portfolios and profiles in order to present and promote their expertise. Photographers can self-promotion and job self-posting. Their photographs are organized in case of graduation events, individual/fashion events and wedding receptions, and photographs' details such as, image details including exchangeable image file format camera model, speed shutter, F-number, ISO, focal length, date and time, are also provided. This system provides function search covering basic and advanced search. The basic search can be done based on the photographer's name, and if required, an advanced search can be done by identifying the type of work, duration, rate or venue, and the output is a list of photographers who meet or nearly meet the user's requirements. This system has a function to invite photographers to work with us through social media. It contains comments, reviews and rating functions that focus members are able to comment on and rate photographers and their performance. Webboard function can be used for exchanging ideas and sharing knowledge. This system provides customer testimonials in order to create trust in the audience. It also makes the audience feel content to use our service once they visit our site. The back-end system consists of the admin functions, the photographers' status confirmation, their profiles and their biographies; and the dashboard module includes statistical reports relating to: numbers of photographers and their statuses and whether they are confirmed and unconfirmed as members; the photographers' portfolios; customers' comments on photographers' performance and photographers' rating scores.

\subsection{System evaluation}

\subsubsection{Evaluation}

System evaluation was performed by a sample group consisting of 30 members of the photography club, freelance photographers or potential customers. The evaluation tool was a questionnaire completed by the participation group who rated the system's abilities on a 5-point Likert scales anchored by 5 as strongly agree to 1 being strongly disagree. The questionnaire was divided into commerce, content, context, and communication [18], [25], [26]. The results of the evaluation will be used to further develop the prototype system prior to the implementation of the real system. The results showed that the overall level of user satisfaction was at score $\bar{x}=4.049$, with the following details:

- Commerce dimension shown in Figure 2(a) was evaluated at a high level $(\bar{x}=3.973)$ with the rating results, respectively from the highest to the lowest being for (a) ease-to-use search engine; (b) well-designed homepage; (c) providing self-promotion function; (d) sufficient report and summary information; (e) well-organized content structure; and (f) ability to manage user information.

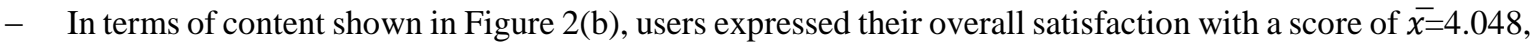
with the rating results ranking from the highest to the lowest for (a) appropriate functions and tools, (b) adequate security features; (c) ability to create portfolios and profiles, (d) proper use of multimedia, (e) up-to-date information; and (f) relevant and useful information.

- Context dimension shown in Figure 2(c) was evaluated and rated overall at a score of $\bar{x}=4.0874$, details as following. Users expressed their satisfaction with the rating results ranging from the highest to the lowest for (a) well-design user interface; (b) standard system design; (c) easy to learn and use; (d) system speed and performance, (e) managing user authorization, (f) providing support function and user manual; and (g) adequacy of navigation system.

- Communication dimension shown in Figure 2(d) was evaluated on an overall level at a score of $\bar{x}=4.086$, with the rating results, respectively from the highest to the lowest being for a) reviewing and rating product and service; (b) providing multi-channel communication; and (c) providing a knowledge sharing zone.

\subsubsection{Lesson learned}

After finishing the evaluation, participants gave their feedback regarding the overall satisfaction of the portal. They elaborated on what they liked most and least, as well as the suggestion for improving the portal. Most participants liked the user interface and standard system design. They applauded the portals' architecture for being simple, understandable, and transparent. Following that, the majority of participants appreciated the feedback mechanism inside the portal, which included ranking and evaluating by their customers. Furthermore, participants applauded the intuitiveness and learnability of the portal. They mentioned that the portal is simple to use for both the first time and for returning users. Additionally, participants stated that the portal was well-designed for multi-channel messaging (online vs offline). Moreover, the security features of the portal were deemed adequate by participants.

On the other hand, some participants expressed confusion about the design of hierarchically organized subject directories, followed perhaps by hypertext browsing, to locate relevant information. If in-context help 
could be provided, they were all for including it in their portal, and believed that users then would take advantage of it. Moreover, participants had experienced difficulty in managing the user information module, such as the uploading feature sup ports few file formats and the maximum upload size was not apparent. They further suggested that this portal prototype should be given the information to complete the process. This system should be improved, according to the participants' suggestions.

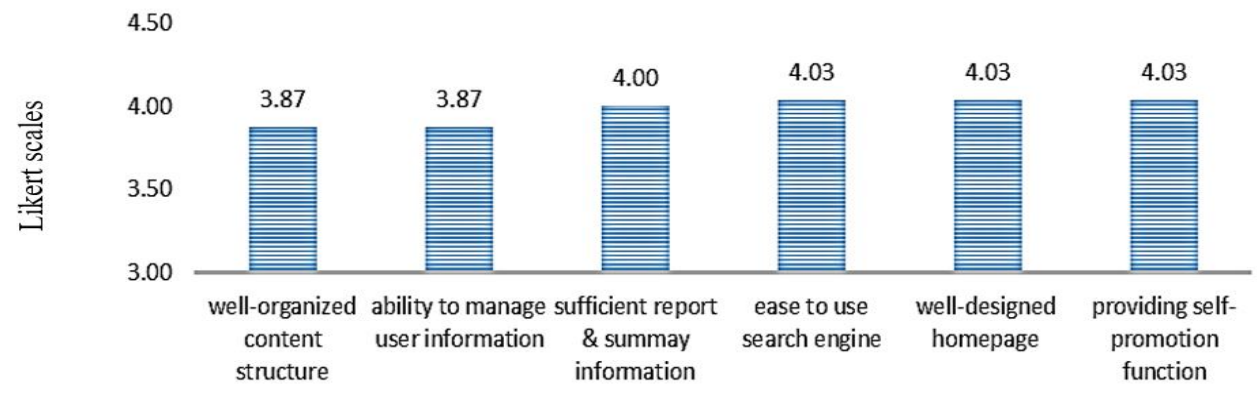

(a)

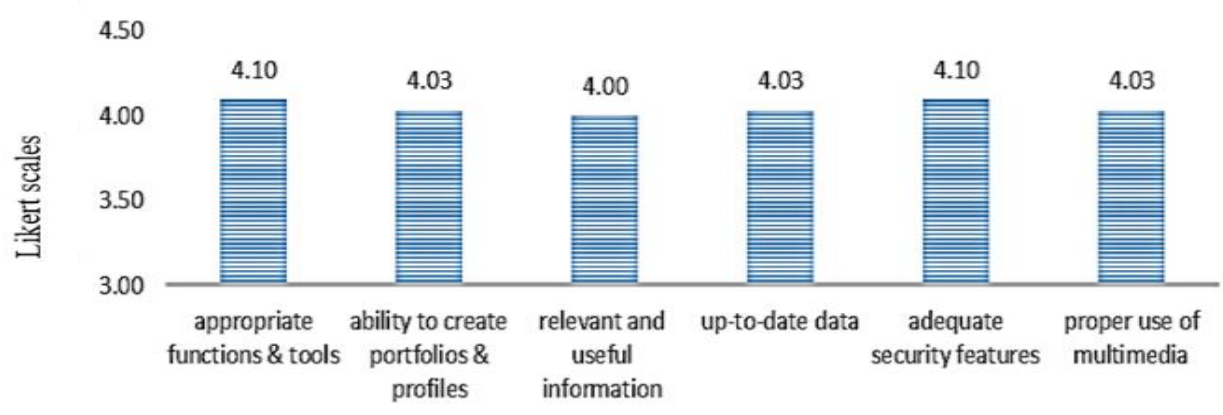

(b)

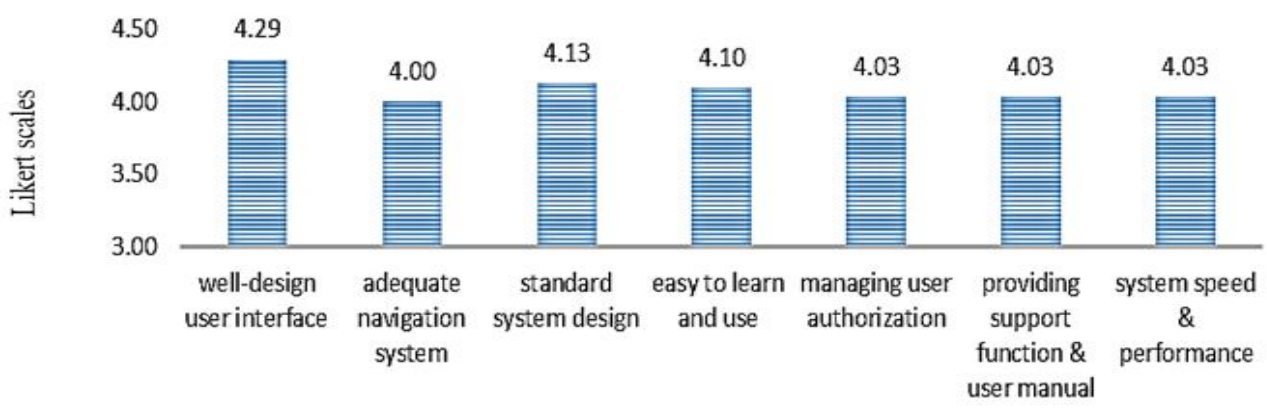

(c)

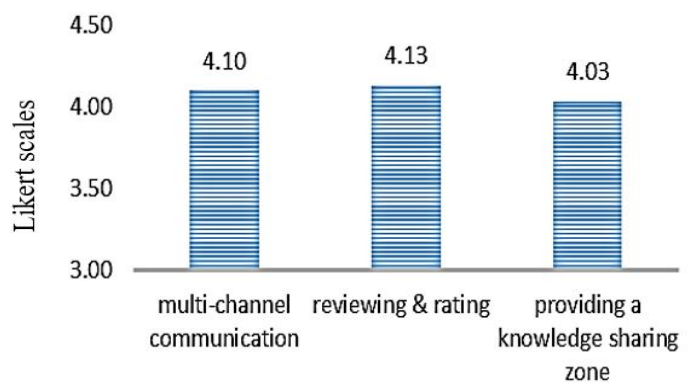

(d)

Figure 2. System evaluation by users based on (a) commerce dimension, (b) content dimension, (c) context dimension, and (d) communication dimension 


\section{DISCUSSION}

The attempt to establish and maintain a web portal to allow freelance community in the Southern region of Thailand to take advantage of emerging technologies was a brave move. However, given the lack of opportunities for freelance community to engage in online business, it was a worthy one. This is understandable given that this was a very forward-looking, and innovative project. It would probably have been better to scope of the portal and to treat it as a pilot project.

Some obstacles for freelance photographers were revealed in this study including the limitation to announcement the photographers' portfolios, and their biographies and performance to a large community of users. Moreover, some difficulties were evident in searching for qualified and experienced photographers since the information presented relating to available photographers might not be reliable. There was also noted to be insufficient vetting of the information uploaded by the photographers since the communication channels in the system are fundamentally informal. These limitations might impact the ability of photographers (sellers of services) selected by customers (buyers of services) to perform the required task to the customers' satisfaction and thus affect the payment of the agreed fee by the customers, the finding which is in line with those of previous studies [27], [28]. Despite the above limitations, this study developed an e-service web portal for freelance photographers and their customers with the aim of establishing an online facility on which photographers could publicize their services and performance to potential customers, who could search for and access information relating to photographers including their portfolios, and on which knowledge could be exchanged relating to photography. The concepts entailed in web portals and e-services were the key elements in the development of the system and ensured that its functions worked correctly and adequately.

Freelance photographers' services are available both offline and online media. The ability to engage their services online offers advantages through cost saving and offers the advantage of being able to contact a wider range of customers and facilitating the development of customer relationships. Nevertheless, there are some limitations in the use of online media [27], [29], for instance, for photographers in the early stages of their career, it is difficult for them to make their work well-known, and for customers, the extent to which they can rely on a particular photographers' services is limited without having accurate information about their past performance with a wider community of users. Moreover, customers' may have to rely on the photographers' portfolio, which may or may not be an accurate reflection of their ability to use photographic equipment in accordance with the customers' objectives. Finally, searching for photographers' biographies based on the required service areas may also be difficult. In Thailand, freelance photographers are only available within certain areas, mainly around the capital or in large cities, while in other regions, there may be a lack of sources of information about both beginner and professional photographers and a lack of channels through which to exchange knowledge or discuss problems. This is consistent with a previous study [2], [30] which emphasized the problems of freelance artists in Australia and eventually developed a local community marketplace for artists to work together along with business establishments. However, that study focused on a purposively selected sample group in a specific area and its findings may not be generalizable beyond its immediate context. It is therefore expected that the system developed will help to create an online community among those interested in photography and who possess the ability to use information technology, especially, e-service technology and web portals, and will extend their ability to both provide and access information relating to photography services.

\section{CONCLUSION}

This study aims to establish an online facility in which freelance photographers can publicize their services and performance to potential customers. The concepts entailed in web portals and e-services were the key elements in the development and ensured that its functions worked efficiently. The practical contribution is effectively design and implementation of an e-service web portal for the freelance community of photography business, and it is a massive step towards promoting the freelance community in Thailand.

There are limitations to this study because the system developed was a prototype and the target group sampled for the assessment of the system were restricted to staff and students within a university. The research is an early stage of an e-service web portal which is specific requirements to the local community. Future studies should, therefore, be extended to the universal e-service web portal, which serves the needs of the international community and users worldwide.

\section{ACKNOWLEDGEMENTS}

The authors gratefully acknowledge research support from Prince of Songkla University Surat Thani Campus. The authors would like to express their gratitude to Mr. Michael Currie, from the Publication Clinic, Research and Development Office, Prince of Songkla University, for help in manuscript preparation. 


\section{REFERENCES}

[1] Thailand Professional Qualification Institute, Qualification Standard in Photo Business. Thailand, $2016, \mathrm{pp} .1-237$.

[2] R. A. L. Krishnamoorthy, A. S. Baharudin, and K. Karkonasasi, "Intention to adaption and influence of using online freelance portal among Malaysians," International Journal of Applied Engineering Research, vol. 11, no. 19, pp. 10020-10026, 2016.

[3] L. Adler, The linked photographers' guide to online marketing and social media [Recurso electrónico]/Lindsay Adler and Rosh Sillars. Boston: Cengage Learning, 2011.

[4] Photoshelter and Agency Access, "The 2013 survey: what buyers want from photographers," New York, 2013

[5] S. K. Shivakumar, A Complete Guide to Portals and User Experience Platforms. Boca Raton: CRC Press, 2015.

[6] J. Damsgaard, "Managing an Internet Portal," Communications of the Association for Information Systems, vol. 9, 2002, doi: 10.17705/1cais.00926

[7] J. Fisher and A. Craig, "Developing business community portals for SMEs - issues of design, development and sustainability," Electronic Markets, vol. 15, no. 2, pp. 136-145, May 2005, doi: 10.1080/10196780500083811.

[8] S. Gounaris and S. Dimitriadis, "Assessing service quality on the Web: Evidence from business-to-consumer portals," Journal of Services Marketing, vol. 17, no. 5, pp. 529-548, Sep. 2003, doi: 10.1108/08876040310486302.

[9] A. C. R. Van Riel, V. Liljander, and P. Jurriëns, "Exploring consumer evaluations of e-services: A portal site," International Journal of Service Industry Management, vol. 12, no. 4, pp. 359-377, Oct. 2001, doi: 10.1108/09564230110405280.

[10] S. Staab et al., "Semantic community web portals," Computer Networks, vol. 33, no. 1, pp. 473-491, Jun. 2000, doi: 10.1016/S13891286(00)00039-6.

[11] J. Reynolds, "eCommerce: A critical review," International Journal of Retail \& Distribution Management, vol. 28, no. 10, pp. 417-444, Nov. 2000, doi: 10.1108/09590550010349253.

[12] K. De Ruyter, M. Wetzels, and M. Kleijnen, "Customer adoption of e-service: An experimental study," International Journal of Service Industry Management, vol. 12, no. 2, pp. 184-207, May 2001, doi: 10.1108/09564230110387542.

[13] H. Surjadjaja, S. Ghosh, and J. Antony, "Determining and assessing the determinants of e-service operations," Managing Service Quality: An International Journal, vol. 13, no. 1, pp. 39-53, Feb. 2003, doi: 10.1108/09604520310456708.

[14] M. Singh, "E-services and their role in B2C e-commerce," Managing Service Quality: An International Journal, vol. 12, no. 6, pp. 434-446, 2002, doi: 10.1108/09604520210451911.

[15] C. Grönroos, F. Heinonen, K. Isoniemi, and M. Lindholm, "The NetOffer model: a case example from the virtual marketspace," Management Decision, vol. 38, no. 4, pp. 243-252, May 2000, doi: 10.1108/00251740010326252.

[16] T. S. Jones and R. C. Richey, "Rapid prototyping methodology in action: A developmental study," Educational Technology Research and Development, vol. 48, no. 2, pp. 63-80, 2000, doi: 10.1007/BF02313401.

[17] I. Sommerville, Software engineering (10th edition). Scotland: Pearson, 2016.

[18] D. Sampson and N. Manouselis, "A flexible evaluation framework for web portals based on multi-criteria analysis," in Web Portals, IGI Global, 2011, pp. 185-211.

[19] A. Sampaio, "Web portal application development technologies," in Encyclopedia of Portal Technologies and Applications, IGI Global, 2011, pp. 1131-1137.

[20] H. H. Bauer, M. Hammerschmidt, and T. Falk, "Measuring the quality of e-banking portals," International Journal of Bank Marketing, vol. 23, no. 2, pp. 153-175, Mar. 2005, doi: 10.1108/02652320510584395.

[21] C. Liu and K. P. Arnett, "Exploring the factors associated with Web site success in the context of electronic commerce," Information and Management, vol. 38, no. 1, pp. 23-33, Oct. 2000, doi: 10.1016/S0378-7206(00)00049-5

[22] S. S. Srinivasan, R. Anderson, and K. Ponnavolu, "Customer loyalty in e-commerce: An exploration of its antecedents and consequences," Journal of Retailing, vol. 78, no. 1, pp. 41-50, Mar. 2002, doi: 10.1016/S0022-4359(01)00065-3.

[23] I. Clarke and T. B. Flaherty, "Web-based B2B portals," Industrial Marketing Management, vol. 32, no. 1, pp. 15-23, Jan. 2003, doi: 10.1016/S0019-8501(01)00199-7.

[24] M. Davydov, Corporate portals and ebusiness integration. New York: McGraw-Hill, 2001.

[25] L. Xiao and S. Dasgupta, "User satisfaction with web portals," in Web Systems Design and Online Consumer Behavior, IGI Global, 2011, pp. 192-204.

[26] B. W. Wirtz, L. Mory, and R. Piehler, "Web 2.0 and digital business models," Springer Berlin Heidelberg, 2014, pp. 751-766.

[27] M. Piscopo, The photographer's guide to marketing and self-promotion. Simon and Schuster, 2017.

[28] V. Orenstein, The photographer's market guide to building your photography business. F+ W Media, Inc., 2010.

[29] L. Hanborough, Social media marketing for publishers. Indianapolis: John Wiley \& Sons, 2012.

[30] X. Ma and S. Yang, "Airtasker and the Australian freelance workers: The reflections on the gig economy," International Journal of Advanced and Applied Sciences, vol. 5, no. 7, pp. 35-45, Jul. 2018, doi: 10.21833/ijaas.2018.07.005.

\section{BIOGRAPHIES OF AUTHORS}

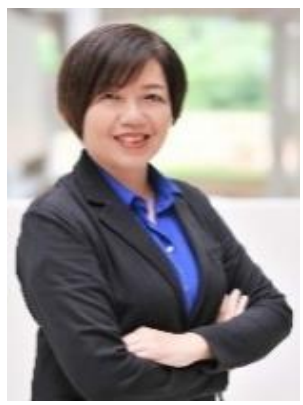

Supaporn Chai-Arayalert (iD $\mathrm{SC}$ S $\mathrm{P}$ is a senior lecturer in the Faculty of Science and Industrial Technology, Prince of Songkla University, Surat Thani Campus, Thailand. She obtained Ph.D. degree in Informatics from the University of Reading in UK. Her teaching and research interests include Information Systems, E-commerce, digital marketing, IT project management, Green IT, and knowledge management. Her research has been published in journals such as Cogent Social Science, International Journal of Emerging Technologies in Learning, Creativity Studies, and Cogent Business \& Management. She can be contacted at email: supaporn.chai@psu.ac.th. 


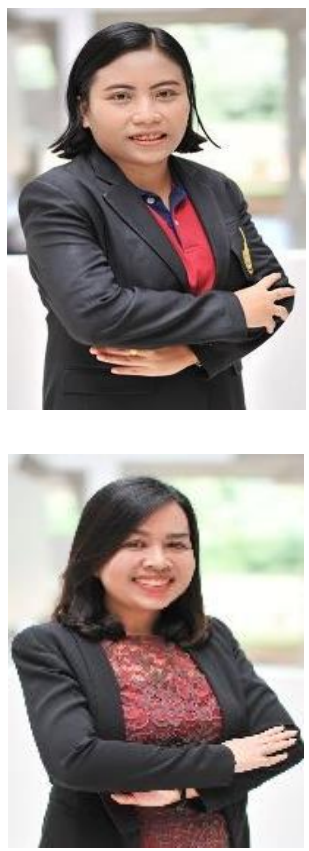

Supattra Puttinaovarat (D) 8 SC $\mathrm{P}$ received the B.B.A. degree (Hons.) and the M.S. degree in management of information technology from the Prince of Songkla University, Thailand, in 2007 and 2010, respectively, and the Ph.D. degree in information technology from the Suranaree University of Technology, Thailand, in 2016. She is currently an Assistant Professor with the Faculty of Science and Industrial Technology, Prince of Songkla University, Surat Thani Campus, Surat Thani, Thailand. Her research interests include flood modeling, geographic information systems, remote sensing, e-learning, and machine learning. She can be contacted at email: supattra.p@psu.ac.th.

Nattaporn Thongsri (D) SC P is currently a lecturer in the faculty of Science and Industrial Technology, Prince of Songkla University, Surat Thani Campus, Thailand. She received Ph.D. degree major in Management Science and Engineering from the School of Management, Huazhong University of Science and Technology, Wuhan, China. Her teaching and research interests include structural equation modelling, technology acceptance, educational informatics and electronic commerce. Her research has been published in journals such as Behaviour \& Information Technology, Innovations in Education and Teaching International, Journal of Systems and Information Technology and The International Journal of Information and Learning Technology. She can be contacted at email: nattaporn.th@psu.ac.th. 